\title{
Quality control material for the detection of somatic mutations in fixed clinical specimens by next-generation sequencing
}

\author{
Catherine I. Dumur, Jorge A. Almenara, Celeste N. Powers and Andrea Ferreira-Gonzalez
}

\begin{abstract}
Background: Targeted next generation sequencing (NGS) technology to assess the mutational status of multiple genes on formalin-fixed, paraffin embedded (FFPE) tumors is rapidly being adopted in clinical settings, where quality control (QC) practices are required. Establishing reliable FFPE QC materials for NGS can be challenging and/or expensive. Here, we established a reliable and cost-effective FFPE QC material for routine utilization in the Ion AmpliSeq ${ }^{\text {TM }}$ Cancer Hotspot Panel v2 (CHP2) assay.

Methods: The performance characteristics of the CHP2 assay were determined by sequencing various cell line mixtures and 55 different FFPE tumors on the lon Torrent PGM platform. A FFPE QC material was prepared from a mixture of cell lines derived from different cancers, comprising single nucleotide variants and small deletions on actionable genes at different allelic frequencies.
\end{abstract}

Results: The CHP2 assay performed with high precision and sensitivity when custom variant calling pipeline parameters where established. In addition, all expected somatic variants in the QC material were consistently called at variant frequencies ranging from $9.1 \%(\mathrm{CV}=11.1 \%)$ to $37.9 \%(\mathrm{CV}=2.8 \%)$.

Conclusions: The availability of a reliable and cost-effective QC material is instrumental in assessing the performance of this or any targeted NGS assay that detects somatic variants in fixed solid tumor specimens.

\section{Background}

The numerous cancer genome characterization efforts that have emerged in the past years [1-3] have promoted the development of targeted cancer therapeutics [4], including single or combined inhibitory agents [5], which reportedly are beneficial to individuals who have tumors harboring specific somatic mutations in genes encoding for proteins involved in cell growth, proliferation, and survival signaling pathways [6-9]. Thus, molecular testing to identify such mutations in clinical specimens to assess patient eligibility for targeted therapies has become standard practice in the management of oncology patients.

The recent technological advances in next-generation sequencing (NGS) and the applications in the field of oncology are revolutionizing clinical testing for personalized treatment decisions for oncology patients [10]; as well as the translational research field, where somatic

\footnotetext{
* Correspondence: catherine.dumur@vcuhealth.org

Department of Pathology, Virginia Commonwealth University, Clinical

Support Center, Room 247, 403 North 13th Street, Richmond, VA 23298, USA
}

variant findings may enhance the development of novel targeted cancer therapeutics, which could benefit individuals with tumors harboring such mutations. A variety of different NGS-based assays have been developed for mutation identification that have the ability to detect all mutation types, including single nucleotide variants (SNVs), copy number variants (CNVs), insertion/deletions (Indels) and translocations, in many samples and many genomic regions simultaneously, while providing a digital readout of mutation frequencies.

The advent of NGS benchtop sequencers has allowed the rapid adoption of molecular testing for somatic mutations in clinical settings [11-13]. Thus, amplifying discrete or targeted regions of the genome has allowed for the development of panels of "amplicon sequencing." As an example, the Ion AmpliSeq ${ }^{\text {mo }}$ Cancer Hotspot Panel v2 (Life Technologies, Carlsbad, CA), which targets 207 exonic regions across 50 cancer-relevant genes, is producing robust results starting from 1 to $10 \mathrm{ng}$ of DNA isolated from formalin-fixed, paraffin 
embedded (FFPE) specimens [14]. Such an assay can yield up to 1 gigabyte $(\mathrm{Gb})$ of DNA sequence in the Ion Torrent Personal Genome Machine ${ }^{\mathrm{mix}}$ (PGM), depending on the chip used to run the sequencing reaction, in short DNA fragments. Similarly, the TruSeq Amplicon - Cancer Panel (Illumina, Inc., San Diego, CA), assay allows the sequencing of mutational hotspots located in 212 exonic regions corresponding to 48 cancer-related genes on the Illumina MiSeq, from 250 ng of DNA sample. These NGS platforms provide the benefit of targeting multiple genomic regions in a single reaction, thus lowering the cost of the assay and allowing for testing multiple genes in small samples.

However, the performance characteristics of NGSbased clinical assays needs to be assessed during the assay validation process, and ensured during routine clinical runs [15]. One of the remaining challenges for NGS-based clinical assays is the availability of robust, cost effective, reference or quality control (QC) material. Access to such material is crucial to be able to generate confident NGS results, while managing potential workflow variability from sample extraction to sequencing, data analysis pipeline and variant calling.

In this study we describe the analytical and clinical validation of a 50-gene NGS assay, the Ion AmpliSeq ${ }^{\text {tix }}$ Cancer Hotspot Panel v2 (CHP2), performed on the Ion Torrent PGM, for clinical testing, as well as the development of a robust, and relatively low cost, QC material to assess performance characteristics during routine clinical runs.

\section{Materials and methods Cell lines}

DNA isolated from fresh-frozen, as well as from formalinfixed, paraffin-embedded (FFPE) cell pellets from melanoma (SK-MEL28), pancreatic (MIA-PaCa-2), colon (HCT116), and lung (H1975) cancer cell lines was used. All the cell lines were obtained from American Type Culture Collection (ATCC-http://www.atcc.org, Manassas, VA). Each individual cell line DNA sample was sequenced alone or combined with others in different proportions, resulting in various sample mixes harboring different mutations, at different frequencies.

\section{Tissue specimens}

Fifty five de-identified archival DNA samples isolated from FFPE tissue blocks containing greater than $40 \%$ neoplastic cells (43 non-small cell lung carcinoma (NSCLC), 4 colorectal cancer, and 8 melanoma cases) with known mutational status for the KRAS, EGFR and BRAF (including 25 Negative and 30 Positive for mutations in at least one of these three genes) were used for the clinical validation of the CHP2 assay. These DNA samples had previously been isolated from tumor-enriched samples by manual Microdissection, when indicated by a pathologist.

\section{Single gene mutation assays}

KRAS mutations in codons 12 and 13 were detected by Sanger sequencing, preceded by a Co-amplification at Lower Denaturation-temperature PCR (COLD-PCR) [16] step for allele enrichment, whereas EGFR mutations in exons 18 to 21 were detected by Scorpion primerprobes and Amplification Refractory Mutation Screening $\left(\mathrm{ARMS}^{\circ}\right)$ [17] technology using the real-time PCR-based EGFR RGQ PCR assay (Qiagen, Valencia, CA) according to the manufacturer's recommendations. BRAF mutations in the V600 codon, as well as specific SMAD4 and $R E T$ variants, were detected by multiplex allele-specific PCR (AS-PCR) reactions that co-amplify the variant sequence and an upstream conserved sequence, where amplicons were detected by capillary electrophoresis using Lab-on-a-Chip technology. The primers used for the multiplex AS-PCR amplification for BRAF, SMAD4 and $R E T$ specific variants are listed in Table 1, along with the resulting amplicon sizes.

\section{DNA isolation}

All tissue H\&E stained slides were reviewed by a pathologist who assessed percent tumor content and delineated the tumor area for manual microdissection, if needed. Ten-micron unstained FFPE slides were then manually dissected, when indicated, and DNA was extracted using the DNA mini kit as described by the manufacturer (Qiagen, Germantown, MD). The same DNA extraction method was used for the fresh-frozen and FFPE cell line pellets and from specimens subjected to laser capture microdissection (LCM). Double-stranded DNA (dsDNA) yield and concentration was assessed by fluorometry on the Qubit 2.0 instrument (Life Technologies, Carlsbad, CA)

\section{Library preparation}

The Ion AmpliSeq ${ }^{\text {Ta }}$ Cancer Hotspot Panel v2 (CHP2) was used to generate 207 amplicons covering over 2,800 hotspots, indexed in the COSMIC database, in 50 cancer-related genes, from 1 to $10 \mathrm{ng}$ of dsDNA for each sample, using additional PCR cycles for the lowest dsDNA concentrations. The multiplexed amplicons were then used to generate barcoded libraries using the Ion AmpliSeq ${ }^{\mathrm{Tm}}$ Library Kit 2.0 and the Ion Xpress ${ }^{\mathrm{mm}}$ barcoded adapters (Life Technologies, Carlsbad, CA). Amplified libraries were quantitated following the manufacturer's recommendations. Barcoded libraries were combined to a final concentration of $7 \mathrm{pM}$, to achieve optimal yield of clonal templated Ion Sphere ${ }^{\mathrm{mt}}$ Particles (ISPs), for emulsion PCR (emPCR) and further ISP enrichment following the manufacturer's recommendations. Sequencing 
Table 1 ASPCR Primers

\begin{tabular}{|c|c|c|}
\hline Amplicon Name & Primer Sequence $\left(5^{\prime}-3^{\prime}\right)$ & $\begin{array}{l}\text { Amplicon } \\
\text { Size (bp) }\end{array}$ \\
\hline \multirow[t]{2}{*}{ BRAF_conserved } & $\begin{array}{l}\text { BRAF-F1: } \\
\text { TGCTTGCTCTGATAGGA }\end{array}$ & 241 \\
\hline & $\begin{array}{l}\text { BRAF_R: } \\
\text { CTAGTAACTCAGCAGCA }\end{array}$ & \\
\hline \multirow[t]{2}{*}{ BRAF_V600E } & $\begin{array}{l}\text { BRAF-F2: } \\
\text { TGGTCTAGCTACAGA }\end{array}$ & 141 \\
\hline & $\begin{array}{l}\text { BRAF_R: } \\
\text { CTAGTAACTCAGCAGCA }\end{array}$ & \\
\hline \multirow[t]{2}{*}{ SMAD4_conserved } & $\begin{array}{l}\text { SMAD4_F1: } \\
\text { TTGTCTTITCTTAGGGC }\end{array}$ & 286 \\
\hline & $\begin{array}{l}\text { SMAD4_R: } \\
\text { AAGATAGTTCTITCTTITGG }\end{array}$ & \\
\hline \multirow[t]{2}{*}{ SMAD4_48586344_C > T } & $\begin{array}{l}\text { SMD4_F2: } \\
\text { ATTAGTGGTGATTGAAAT }\end{array}$ & 181 \\
\hline & $\begin{array}{l}\text { SMAD4_R: } \\
\text { AAGATAGTTCTITTCTITGG }\end{array}$ & \\
\hline \multirow[t]{2}{*}{ RET_conserved } & $\begin{array}{l}\text { RET_F1: } \\
\text { GTGCTATITICCTCACA }\end{array}$ & 268 \\
\hline & $\begin{array}{l}\text { RET_R: } \\
\text { AGGGCTATAAAAAGCTTAG }\end{array}$ & \\
\hline \multirow[t]{2}{*}{ RET_43615612_A > G } & $\begin{array}{l}\text { RET_F2: } \\
\text { GCTTGTCCCGG }\end{array}$ & 176 \\
\hline & $\begin{array}{l}\text { RET_R: } \\
\text { AGGGCTATAAAAAGCTTAG }\end{array}$ & \\
\hline
\end{tabular}

was performed on $316^{\mathrm{m}}$ chips run on the Ion Torrent PGM and analyzed with the Torrent Suite v4.0.2 Software. The February 2009 assembly of the human genome (hg19, GRCh37 Genome Reference Consortium Human Reference 37 ) was used as a reference.

\section{Determining the Limit of Detection (LoD)}

DNA mixes from the four fresh-frozen cell line pellets used in this study were further diluted in DNA isolated from a de-identified normal snap-frozen human placenta to achieve several different variants at different frequencies 39 variants in 24 genes. In addition, DNA isolated from FFPE cell line pellets was combined in different proportions to achieve 37 variants at different frequencies in 23 genes.

\section{Analytical performance evaluation}

Robustness, repeatability and reproducibility were assessed by preparing multiple libraries from the LoD sample mixtures and running them in different $316^{\mathrm{TM}}$ chips. Accuracy was evaluated by comparing variant frequencies obtained from individual cell lines with the results obtained by the Genomics and Bioinformatics Group (GBG) from $\mathrm{NCI}$, by querying the CellMiner database [18]. In addition, libraries from the 55 patient samples and from the well-characterized reference DNA sample NA12878 from the HapMap project [19] were sequenced and compared to single gene mutation assay results to further assess the accuracy of the CHP2 assay.

\section{Data analysis pipeline}

The sequencing data generated by the Ion Torrent PGM was stored and analyzed in the Linux-based Server, based on Ubuntu operating system, connected to the instrument. The file types created during sequencing included: raw image acquisition. DAT files; basecalling, resulting in an unmapped BAM format file; and alignment to the reference genome using the TMAP aligner algorithm, with the output being a BAM file. Output BAM files, along with target regions BED files, were used for variant identification by the VariantCaller plugin. Visualization of the raw alignments was assessed using the Broad's Integrative Genomics Viewer (IGV 2.3.11) [20].

\section{Variant calling}

The Torrent VariantCaller (TVC) plugin was used to identify and evaluate variants. The CHP2 assay was validated with the TVC 4.0 version of the plugin. The TVC 4.0 is designed to call SNVs, multi-nucleotide variants (MNVs), insertions (INS), and deletions (DEL). The analysis pipeline uses FreeBayes, based on user-modifiable parameters, such as coverage, quality, strand bias, and homopolymer length, among others, to discover candidate variant locations, which are subsequently scored using adaptive signal model and filtered. FreeBayes [21] is a haplotype-based variant detector that runs in a Bayesian statistical framework, which is capable of modeling multiallelic loci in sets of individuals with non-uniform copy number. Afterwards, a second module performs assembly of reads to detect long INS and/or DEL (Indels). A set of seven barcoded FFPE cell line mix samples with known variant frequencies were used to establish cutoff values for critical TVC parameters to achieve enough stringency (fewer false positives), while maintaining high sensitivity (fewer false negatives) in the variant calling process. For each critical parameter, z-scores of normally distributed data were calculated to establish cutoff values to be used the custom TVC plugin parameters, which were recorded in a JSON text format. We used the Shapiro-Wilk normality test [22] to assess the normality of the critical parameters distribution.

\section{Quality Control (QC) material}

QC material was prepared by growing the four cell lines in individual T-75 flasks up to right before they reach confluence. Then, cells were scrapped off each flask and pooled together in PBS. This cell mixture was centrifuged for $10 \mathrm{~min}$ at $1800 \mathrm{rpm}$ and the supernatant was decanted. The cell pellet was then resuspended in $500 \mu \mathrm{L}$ of normal human plasma. Fifty $\mu \mathrm{L}$ of thrombin solution (Siemens Healthcare Diagnostics Inc., Tarrytown, NY) were added 
Table 2 Variants identified in DNA isolated from frozen cell line mixes

\begin{tabular}{|c|c|c|c|c|c|c|c|c|c|c|c|c|c|c|c|}
\hline \multirow[b]{2}{*}{ Gene Symbol } & \multirow[b]{2}{*}{ hg19 Coordinates } & \multirow[b]{2}{*}{ Variant Type } & \multirow[b]{2}{*}{ Variant } & \multirow{2}{*}{$\begin{array}{l}\text { Cell Line / } \\
\text { Sample } \\
\text { Name } \\
\text { Freq. (\%) }\end{array}$} & \multirow{2}{*}{$\begin{array}{l}\text { HCT116 } \\
\text { Found }\end{array}$} & \multirow{2}{*}{$\begin{array}{l}\text { MiaPaCa-2 } \\
\text { Found }\end{array}$} & \multirow{2}{*}{$\begin{array}{l}\text { H1975 } \\
\text { Found }\end{array}$} & \multirow{2}{*}{$\begin{array}{l}\text { SK-MEL-28 } \\
\text { Found }\end{array}$} & \multicolumn{2}{|c|}{ 4-Cell Line Mix } & \multirow{2}{*}{$\begin{array}{l}\text { Human } \\
\text { Placenta } \\
\text { Found }\end{array}$} & \multicolumn{2}{|c|}{$\begin{array}{l}\text { 4-Cell Line Mix } \\
\text { (Dil 1:2) }\end{array}$} & \multicolumn{2}{|c|}{$\begin{array}{l}\text { 4-Cell Line Mix } \\
\text { (Dil 1:3) }\end{array}$} \\
\hline & & & & & & & & & Expected & Found & & Expected & Found & Expected & Found \\
\hline$\overline{A B L 1}$ & 133738370 & SNV & G & & 52.4 & N.A. & N.A. & N.A. & 13.1 & $12.6 \pm 0.5$ & N.A. & 6.1 & $6.3 \pm 0.2$ & 4.1 & $4.4 \pm 0.5$ \\
\hline$A P C$ & 112175770 & SNV & A & & 98.1 & 74.4 & 51.7 & 88.5 & 78.1 & $80.0 \pm 0.9$ & 2.1 & 40.7 & $40.8 \pm 0.9$ & 27.8 & $29.4 \pm 0.8$ \\
\hline ATM & 108138003 & SNV & C & & N.A. & N.A. & N.A. & N.A. & N.A. & N.A. & 55.8 & 27.9 & $32.1 \pm 0.2$ & 37.2 & $40.6 \pm 0.4$ \\
\hline BRAF & 140453136 & SNV & A & & N.A. & N.A. & N.A. & 99.3 & 24.8 & $21.7 \pm 4.0$ & N.A. & 12.3 & $13.7 \pm 0.2$ & 8.2 & $9.6 \pm 0.2$ \\
\hline CDKN2A & 21971153 & SNV & $\mathrm{T}$ & & N.A. & N.A. & 96.4 & N.A. & 24.1 & $35.7 \pm 2.6$ & N.A. & 16.9 & $10.4 \pm 1.1$ & 11.3 & $8.4 \pm 0.9$ \\
\hline CSFIR & 149433596 & SNV & C & & 99.6 & 99.3 & 100.0 & N.A. & 74.7 & $58.6 \pm 4.5$ & 90.5 & 72.9 & $68.8 \pm 0.6$ & 78.8 & $80.5 \pm 1.2$ \\
\hline CSF1R & 149433597 & SNV & $\mathrm{T}$ & & 99.6 & 99.1 & 100.0 & N.A. & 74.7 & $62.3 \pm 9.8$ & 93.2 & 74.3 & $76.9 \pm 0.7$ & 80.6 & $85.7 \pm 0.8$ \\
\hline CTNNB1 & 41266134 & DEL & $\mathrm{CTT}$ & & 50.2 & N.A. & N.A. & N.A. & 12.5 & $10.7 \pm 1.8$ & N.A. & 4.7 & $4.8 \pm 0.6$ & 3.2 & $3.1^{a} \pm 0.1$ \\
\hline EGFR & 55242487 & SNV & $\mathrm{T}$ & & N.A. & N.A. & N.A. & 99.3 & 24.8 & $22.8 \pm 2.6$ & N.A. & 12.3 & $13.4 \pm 0.1$ & 8.2 & $8.0 \pm 0.6$ \\
\hline EGFR & 55249063 & SNV & A & & 100.0 & 23.2 & 70.6 & 100.0 & 73.4 & $75.3 \pm 1.7$ & 97.6 & 85.9 & $84.4 \pm 0.7$ & 89.8 & $90.1 \pm 0.3$ \\
\hline EGFR & 55249071 & SNV & $\mathrm{T}$ & & N.A. & N.A. & 70.7 & N.A. & 17.7 & $27.1 \pm 2.5$ & N.A. & 12.7 & $13.6 \pm 1.1$ & 8.4 & $8.9 \pm 1.2$ \\
\hline EGFR & 55259515 & SNV & G & & N.A. & N.A. & 56.7 & N.A. & 14.2 & $17.8 \pm 0.7$ & N.A. & 9.2 & $8.8 \pm 1.3$ & 6.1 & $6.4 \pm 0.5$ \\
\hline ERBB4 & 212812097 & SNV & G & & 100.0 & N.A. & 75.9 & N.A. & 44.0 & $54.0 \pm 0.2$ & 62.9 & 58.4 & $46.8 \pm 1.6$ & 59.9 & $59.0 \pm 2.3$ \\
\hline FGFR3 & 1807894 & SNV & A & & 100.0 & 100.0 & 99.6 & 100.0 & 99.9 & $99.6 \pm 0.2$ & 100.0 & 99.9 & $99.9 \pm 0.1$ & 99.9 & $99.8 \pm 0.1$ \\
\hline FLT3 & 28602367 & SNV & A & & 46.9 & N.A. & N.A. & N.A. & 11.7 & $15.4 \pm 3.2$ & N.A. & 8.8 & $7.0 \pm 0.3$ & 5.9 & $6.4 \pm 0.8$ \\
\hline FLT3 & 28610183 & SNV & C & & 100.0 & 66.5 & 99.6 & 69.2 & 83.8 & $80.9 \pm 1.1$ & 100.0 & 90.9 & $90.8 \pm 0.1$ & 93.9 & $93.4 \pm 0.5$ \\
\hline HRAS & 534242 & SNV & C & & 99.5 & 61.9 & 40.4 & 46.9 & 62.2 & $67.6 \pm 1.1$ & 2.6 & 34.7 & $32.0 \pm 0.2$ & 24.0 & $21.5 \pm 1.2$ \\
\hline$K D R$ & 55946354 & SNV & A & & 48.5 & N.A. & N.A. & N.A. & 12.1 & $15.9 \pm 1.0$ & 51.3 & 33.3 & $34.5 \pm 1.1$ & 39.3 & $41.0 \pm 1.1$ \\
\hline$K D R$ & 55972974 & SNV & $\mathrm{T}$ & & 52.6 & N.A. & N.A. & N.A. & 13.1 & $13.2 \pm 4.3$ & N.A. & 8.1 & $7.3 \pm 0.5$ & 5.4 & $5.1 \pm 0.1$ \\
\hline KRAS & 25398281 & SNV & A & & 46.4 & N.A. & N.A. & N.A. & 11.6 & $11.3 \pm 0.7$ & N.A. & 5.9 & $6.2 \pm 0.4$ & 3.9 & $4.2 \pm 0.1$ \\
\hline KRAS & 25398285 & SNV & $\mathrm{T}$ & & N.A. & 99.9 & N.A. & N.A. & 25.0 & $24.7 \pm 1.2$ & N.A. & 12.8 & $13.7 \pm 0.5$ & 8.5 & $9.5 \pm 0.1$ \\
\hline MET & 116339672 & SNV & $\mathrm{T}$ & & N.A. & 72.9 & N.A. & N.A. & 18.2 & $15.3 \pm 2.0$ & N.A. & 6.9 & $7.9 \pm 0.0$ & 4.6 & $4.8 \pm 0.1$ \\
\hline NOTCH1 & 139390822 & SNV & G & & N.A. & 100.0 & N.A. & N.A. & 25.0 & $22.5 \pm 0.3$ & N.A. & 11.1 & $9.3 \pm 0.2$ & 7.4 & $7.1 \pm 0.1$ \\
\hline PDGFRA & 55141055 & SNV & G & & 99.7 & 100.0 & 99.7 & 100.0 & 99.8 & $99.9 \pm 0.2$ & 99.9 & 99.8 & $99.9 \pm 0.1$ & 99.8 & $100.0 \pm 0.1$ \\
\hline PDGFRA & 55152040 & SNV & $\mathrm{T}$ & & N.A. & N.A. & 50.8 & N.A. & 12.7 & $11.8 \pm 2.8$ & 3.8 & 8.8 & $7.5 \pm 0.1$ & 7.1 & $6.0 \pm 0.7$ \\
\hline$P \mid K 3 C A$ & 178917005 & SNV & G & & N.A. & N.A. & 100.0 & N.A. & 25.0 & $28.6 \pm 7.6$ & N.A. & 11.6 & $13.9 \pm 0.1$ & 7.8 & $10.2 \pm 0.6$ \\
\hline PIK3CA & 178927410 & SNV & G & & N.A. & N.A. & 45.1 & N.A. & 11.3 & $10.7 \pm 1.2$ & N.A. & 5.8 & $5.9 \pm 0.2$ & 3.9 & $4.0 \pm 0.2$ \\
\hline PIK3CA & 178952085 & SNV & G & & 47.7 & N.A. & N.A. & N.A. & 11.9 & $11.3 \pm 2.3$ & N.A. & 4.9 & $6.4 \pm 0.4$ & 3.2 & $3.9^{\mathrm{a}} \pm 0.1$ \\
\hline PTEN & 89711881 & SNV & G & & N.A. & N.A. & N.A. & 99.3 & 24.8 & $24.3 \pm 1.0$ & N.A. & 11.8 & $9.5 \pm 0.8$ & 7.9 & $8.4 \pm 0.6$ \\
\hline RET & 43613843 & SNV & $\mathrm{T}$ & & 100.0 & 65.8 & 100.0 & N.A. & 66.4 & $70.8 \pm 2.1$ & 100.0 & 86.1 & $86.8 \pm 0.6$ & 90.7 & $91.3 \pm 0.5$ \\
\hline
\end{tabular}


Table 2 Variants identified in DNA isolated from frozen cell line mixes (Continued)

\begin{tabular}{|c|c|c|c|c|c|c|c|c|c|c|c|c|c|c|}
\hline RET & 43615612 & SNV & G & 45.2 & N.A. & N.A. & N.A. & 11.3 & $15.1 \pm 0.3$ & N.A. & 7.4 & $7.2 \pm 0.3$ & 5.0 & $2.9 \pm 0.5$ \\
\hline RET & 43615633 & SNV & G & N.A. & 64.5 & N.A. & N.A. & 16.1 & $14.1 \pm 0.0$ & N.A. & 7.1 & $7.6 \pm 0.5$ & 4.7 & $3.7 \pm 1.1$ \\
\hline SMAD4 & 48586344 & SNV & $\mathrm{T}$ & 47.6 & N.A. & N.A. & N.A. & 11.9 & $17.2 \pm 1.4$ & N.A. & 8.1 & $6.5 \pm 0.2$ & 5.4 & $4.9 \pm 0.2$ \\
\hline SMARCB1 & 24176287 & SNV & A & 50.7 & N.A. & 40.8 & N.A. & 22.9 & $22.0 \pm 2.3$ & N.A. & 11.8 & $14.6 \pm 0.1$ & 7.9 & $10.7 \pm 0.4$ \\
\hline$S M O$ & 128846374 & SNV & A & 52.6 & N.A. & N.A. & N.A. & 13.1 & $10.5 \pm 1.5$ & N.A. & 5.8 & $7.8 \pm 2.0$ & 3.9 & $4.4 \pm 0.2$ \\
\hline TP53 & 7577025 & SNV & $\mathrm{T}$ & N.A. & N.A. & N.A. & N.A. & N.A. & N.A. & 79.0 & 39.5 & $29.1 \pm 1.5$ & 52.6 & $41.4 \pm 1.1$ \\
\hline TP53 & 7577120 & SNV & A & N.A. & N.A. & 99.9 & N.A. & 25.0 & $31.6 \pm 2.6$ & N.A. & 16.7 & $20.8 \pm 0.8$ & 11.1 & $16.0 \pm 0.1$ \\
\hline TP53 & 7577539 & SNV & $\mathrm{T}$ & N.A. & 99.5 & N.A. & N.A. & 24.9 & $18.8 \pm 0.7$ & N.A. & 9.6 & $11.3 \pm 0.1$ & 6.4 & $9.1 \pm 0.1$ \\
\hline TP53 & 7579472 & SNV & G & 94.2 & N.A. & 94.2 & N.A. & 47.1 & $63.6 \pm 8.9$ & 20.4 & 45.1 & $54.3 \pm 2.3$ & 36.9 & $42.7 \pm 1.7$ \\
\hline
\end{tabular}




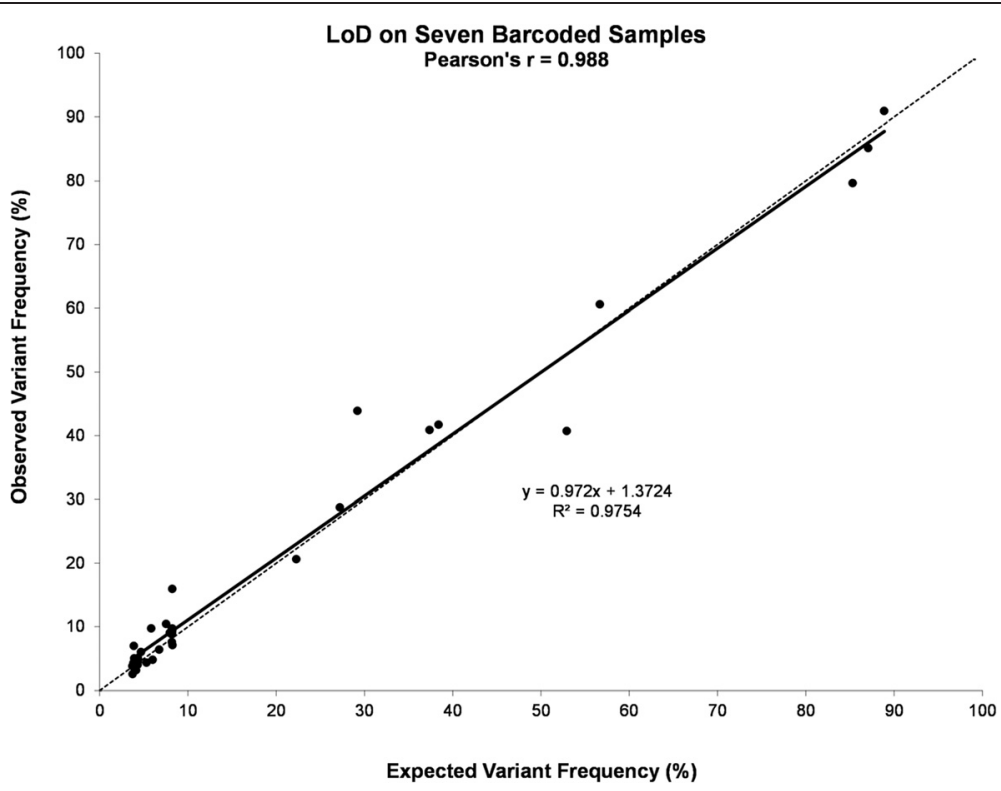

Fig. 1 Limit of Detection (LoD) and linearity of the CHP2 assay. DNA isolated from four fresh-frozen cell line pellets was further diluted in DNA isolated from a de-identified normal human placenta. Variants were identified at the expected frequencies, down to $3 \%$ mutant DNA in the context of normal DNA for fresh-frozen samples, when barcoding up to 7 samples. Pearson correlation is shown. Dotted line denotes the equality line

to the cell pellet/plasma mixture to allow a clot to form. The cell-containing clot was further fixed in formalin for $9 \mathrm{~h}$ (typical fixation time for human tissues in our laboratory), and embedded in paraffin following the routine processing for fine-needle aspiration (FNA) cell pellets. DNA was isolated from a single $10-\mu \mathrm{m}$ section from the cell mixture block, in parallel with patient samples in each batch of samples, and was sequenced in every run as an individual barcoded library with six more libraries from patient samples in $316^{\mathrm{ma}}$ chips. For the QC material, variants and their frequencies were first assessed by sequencing this material in 10 consecutive runs on the Ion Torrent PGM to establish the performance characteristics (i.e., Mean, +2SD, +3SD, etc....) of each variant. After implementing this quality control material in clinical runs, the same variants and their frequencies were monitored over time using LeveyJennings control charts.

\section{Results}

Analytical performance characteristics

From the DNA dilution experiments, where DNA isolated from the four fresh-frozen cell line pellets was further diluted in DNA isolated from a de-identified
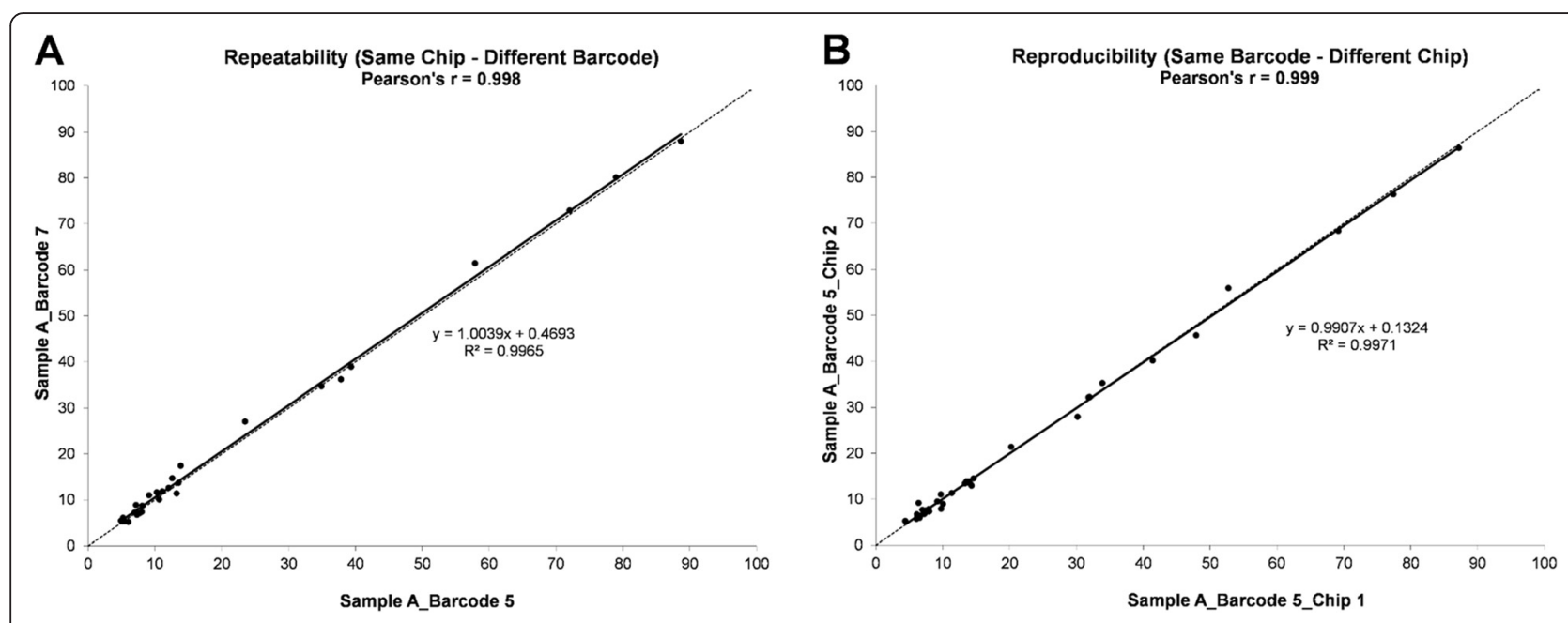

Fig. 2 Precision of the CHP2 assay. A representative sample run using different barcodes on the same chip to assess repeatability (a), or the same barcode on different chips to assess reproducibility $(\mathbf{b})$. Pearson correlation is shown. Dotted line denotes the equality line 
Table 3 Variants identified in DNA isolated from FFPE cell line mixes

\begin{tabular}{|c|c|c|c|c|c|c|c|c|c|c|c|c|}
\hline \multirow[b]{2}{*}{ Gene Symbol } & \multirow[b]{2}{*}{ hg19 Coordinates } & \multirow[b]{2}{*}{ Variant Type } & \multirow[b]{2}{*}{ Variant } & \multirow{2}{*}{$\begin{array}{l}\text { Cell Line/Sample Name } \\
\text { Frequency (\%) }\end{array}$} & \multirow{2}{*}{$\begin{array}{l}\text { HCT116 } \\
\text { Found }\end{array}$} & \multirow{2}{*}{$\begin{array}{l}\text { MiaPaCa-2 } \\
\text { Found }\end{array}$} & \multirow{2}{*}{$\begin{array}{l}\mathrm{H} 1975 \\
\text { Found }\end{array}$} & \multirow{2}{*}{$\begin{array}{l}\text { SK-MEL-28 } \\
\text { Found }\end{array}$} & \multicolumn{2}{|c|}{ 4-Cell Line Mix } & \multicolumn{2}{|c|}{ H1975 Dil in MiaPaCa-2 (1:14) } \\
\hline & & & & & & & & & Expected & Found & Expected & Found \\
\hline$A B L 1$ & 133738370 & SNV & G & & 37.0 & N.A. & N.A. & N.A. & 9.3 & $12.4 \pm 2.6$ & 0.0 & N.A. \\
\hline$A P C$ & 112175770 & SNV & A & & 98.0 & 72.7 & 36.5 & 91.3 & 74.6 & $78.4 \pm 1.2$ & 70.2 & $65.4 \pm 1.4$ \\
\hline BRAF & 140453136 & SNV & A & & N.A. & N.A. & N.A. & 100.0 & 25.0 & $21.1 \pm 2.5$ & 0.0 & N.A. \\
\hline CDKN2A & 21971153 & SNV & $\mathrm{T}$ & & N.A. & N.A. & 98.8 & N.A. & 24.7 & $17.9 \pm 0.6$ & $100.0^{\mathrm{a}}$ & $98.6 \pm 0.9$ \\
\hline CSF1R & 149433596 & SNV & C & & 100.0 & 100.0 & 100.0 & N.A. & 75.0 & $61.4 \pm 2.6$ & 100.0 & $99.9 \pm 0.2$ \\
\hline CSFIR & 149433597 & SNV & $\mathrm{T}$ & & 95.7 & 96.1 & 97.2 & N.A. & 72.3 & $58.0 \pm 3.7$ & 96.2 & $97.2 \pm 0.9$ \\
\hline CTNNB1 & 41266134 & DEL & $\mathrm{CTT}$ & & 44.9 & N.A. & N.A. & N.A. & 11.2 & $12.9 \pm 1.6$ & 0.0 & N.A. \\
\hline EGFR & 55242487 & SNV & $\mathrm{T}$ & & N.A. & N.A. & N.A. & 100.0 & 25.0 & $20.9 \pm 0.1$ & 0.0 & N.A. \\
\hline$E G F R$ & 55249063 & SNV & A & & 100.0 & 35.6 & 75.3 & 100.0 & 77.7 & $74.0 \pm 3.2$ & 38.4 & $48.1 \pm 0.6$ \\
\hline$E G F R$ & 55249071 & SNV & $\mathrm{T}$ & & N.A. & N.A. & 74.8 & N.A. & 18.7 & $17.9 \pm 0.9$ & 5.2 & $30.4 \pm 1.3$ \\
\hline$E G F R$ & 55259515 & SNV & G & & N.A. & N.A. & 71.7 & N.A. & 17.9 & $13.1 \pm 2.3$ & 5.0 & $21.8 \pm 0.8$ \\
\hline ERBBA & 212812097 & SNV & G & & 100.0 & N.A. & 72.3 & N.A. & 43.1 & $45.2 \pm 3.7$ & 5.1 & $26.8 \pm 1.1$ \\
\hline FGFR3 & 1807894 & SNV & A & & 100.0 & 100.0 & 100.0 & 100.0 & 100.0 & $100.0 \pm 0.0$ & 100.0 & $100.0 \pm 0.0$ \\
\hline FLT3 & 28602367 & SNV & A & & 49.5 & N.A. & N.A. & N.A. & 12.4 & $17.8 \pm 0.8$ & 0.0 & N.A. \\
\hline FLT3 & 28610183 & SNV & C & & 100.0 & 64.3 & 100.0 & 65.2 & 82.4 & $81.1 \pm 0.8$ & 66.8 & $69.0 \pm 0.9$ \\
\hline HRAS & 534242 & SNV & $C$ & & 98.9 & 47.8 & 38.9 & 48.5 & 58.5 & $60.6 \pm 2.5$ & 47.2 & $48.2 \pm 2.9$ \\
\hline$K D R$ & 55946354 & SNV & A & & 47.9 & N.A. & N.A. & N.A. & 12.0 & $17.9 \pm 1.2$ & 0.0 & N.A. \\
\hline$K D R$ & 55972974 & SNV & $T$ & & 47.1 & N.A. & N.A. & N.A. & 11.8 & $16.8 \pm 1.1$ & 0.0 & N.A. \\
\hline KRAS & 25398281 & SNV & A & & 47.7 & N.A. & N.A. & N.A. & 11.9 & $12.1 \pm 1.8$ & 0.0 & N.A. \\
\hline KRAS & 25398285 & SNV & $\mathrm{T}$ & & N.A. & 100.0 & N.A. & N.A. & 25.0 & $36.6 \pm 1.2$ & 93.0 & $80.3 \pm 1.4$ \\
\hline MET & 116339672 & SNV & $T$ & & N.A. & 70.3 & N.A. & N.A. & 17.6 & $19.2 \pm 0.8$ & 65.4 & $43.2 \pm 1.1$ \\
\hline NOTCHI & 139390822 & SNV & G & & N.A. & 100.0 & N.A. & N.A. & 25.0 & $33.4 \pm 1.1$ & 93.0 & $70.6 \pm 1.5$ \\
\hline PDGFRA & 55141055 & SNV & G & & 100.0 & 100.0 & 100.0 & 100.0 & 100.0 & $100.0 \pm 0.0$ & 100.0 & $100.0 \pm 0.0$ \\
\hline PDGFRA & 55152040 & SNV & $\mathrm{T}$ & & N.A. & N.A. & 51.3 & N.A. & 12.8 & $8.7 \pm 0.2$ & 3.6 & $18.1 \pm 1.4$ \\
\hline PIK3CA & 178917005 & SNV & G & & N.A. & N.A. & 100.0 & N.A. & 25.0 & $14.7 \pm 0.9$ & 7.0 & $28.0 \pm 0.8$ \\
\hline PIK3CA & 178927410 & SNV & G & & N.A. & N.A. & 47.1 & N.A. & 11.8 & $8.8 \pm 0.0$ & 3.3 & $13.5 \pm 1.0$ \\
\hline PIK3CA & 178952085 & SNV & G & & 47.7 & N.A. & N.A. & N.A. & 11.9 & $12.3 \pm 1.0$ & 0.0 & N.A. \\
\hline PTEN & 89711881 & SNV & G & & N.A. & N.A. & N.A. & 100.0 & 25.0 & $18.8 \pm 1.9$ & 0.0 & N.A. \\
\hline RET & 43613843 & SNV & $\mathrm{T}$ & & 100.0 & 67.5 & 100.0 & N.A. & 66.9 & $70.6 \pm 2.8$ & 69.8 & $76.2 \pm 1.5$ \\
\hline RET & 43615612 & SNV & G & & 49.1 & N.A. & N.A. & N.A. & 12.3 & $14.6 \pm 2.4$ & 0.0 & N.A. \\
\hline RET & 43615633 & SNV & G & & N.A. & 65.1 & N.A. & N.A. & 16.3 & $22.8 \pm 0.1$ & 60.5 & $44.9 \pm 1.5$ \\
\hline SMAD4 & 48586344 & SNV & $\mathrm{T}$ & & 50.6 & N.A. & N.A. & N.A. & 12.7 & $15.9 \pm 1.6$ & 0.0 & N.A. \\
\hline
\end{tabular}


Table 3 Variants identified in DNA isolated from FFPE cell line mixes (Continued)

\begin{tabular}{|c|c|c|c|c|c|c|c|c|c|c|c|}
\hline SMARCB1 & 24176287 & SNV & $A$ & 52.1 & N.A. & 46.3 & N.A. & 24.6 & $20.2 \pm 0.6$ & 3.2 & $15.6 \pm 1.0$ \\
\hline SMO & 128846374 & SNV & A & 51.0 & N.A. & N.A. & N.A. & 12.8 & $12.7 \pm 1.8$ & 0.0 & N.A. \\
\hline TP53 & 7577120 & SNV & A & N.A. & N.A. & 100.0 & N.A. & 25.0 & $20.7 \pm 0.8$ & 7.0 & $32.8 \pm 1.6$ \\
\hline TP53 & 7577539 & SNV & $\mathrm{T}$ & N.A. & 99.9 & N.A. & N.A. & 25.0 & $27.6 \pm 1.1$ & 92.9 & $67.8 \pm 1.4$ \\
\hline TP53 & 7579472 & SNV & G & 84.2 & N.A. & 90.8 & N.A. & 43.8 & $57.6 \pm 8.3$ & 6.4 & $37.9 \pm 5.2$ \\
\hline
\end{tabular}

N.A., Not Applicable; a, the MiaPaCa-2 cell line has a homozygous deletion of the CDKN2A gene 
normal human placenta, we were able to detect the variants, both SNV and DEL, at the frequencies listed in Table 2 . Since variants with frequencies near $3 \%$ were called only $90 \%$ of the time, we established the limit of detection (LoD) at $4 \%$ mutant DNA in the context of normal DNA for fresh-frozen samples, which were detected $100 \%$ of the time when barcoding up to seven samples with an average coverage of near 2000X per sample (Fig. 1). In addition, the same samples run using different barcodes within the same chip, or the same barcode on different chips, showed excellent correlations indicating high repeatability and reproducibility, respectively (Fig. 2).

From the DNA dilution experiments, where DNA isolated from different FFPE cell line pellets was mixed in different proportions, we were able to detect the variants, at different frequencies (Table 3) without affecting the LoD found with DNA isolated from fresh-frozen specimens, when barcoding up to seven samples with an average coverage of near 1300X per sample.

In terms of accuracy, we correlated the variant findings for the HCT116 and SK-MEL-28 cell lines analyzed in this study with the results obtained by the Genomics and Bioinformatics Group (GBG) from NCI, by querying the CellMiner database [18]. This database contains genomic information on the cell lines from the NCI-60 project. These cell lines have been intensely investigated, and a comprehensive analysis of coding variants in these cell lines have been identified by whole exome sequencing (WES). Thus, we found that all but two variants had previously been identified by WES. In the HCT116 cell line, two variants were not found on the CellMiner database: SMAD4_48586344_C > T and RET_43615612_A > G.

The variant in the SMAD4 gene is located in an intronic region; therefore it may not have been detected by WES. In order to validate the presence of this variant in our cell line, we designed a multiplex allelespecific PCR (ASPCR) assay to assess the presence of such variant, which, according to our results, seemed to be found in our clone of HCT116 cells, in a heterozygous fashion. Primers were designed to co-amplify a conserved region of the SMAD4 gene (286 bp), encompassing the $\mathrm{C}>\mathrm{T}$ variant, and a variant-specific amplicon (181 bp) in the same reaction tube. Two PCR master-mixes were designed: one that would detect the variant, and another one that would detect the normal sequence in that position. Similarly, primers were designed to co-amplify a conserved region of the RET gene (268 bp), encompassing the $A>G$ variant, and a variant-specific amplicon (176 bp) in the same reaction tube. As shown on Fig. 3, HCT116, but not the other cell lines, showed evidence of the variant, confirming our sequencing results.

In addition, we found $100 \%$ agreement with the variants identified by our CHP2 assay in the well-characterized reference DNA sample NA12878 from the HapMap project

\section{SMAD4_48586344_C>T RET_43615612_A>G}
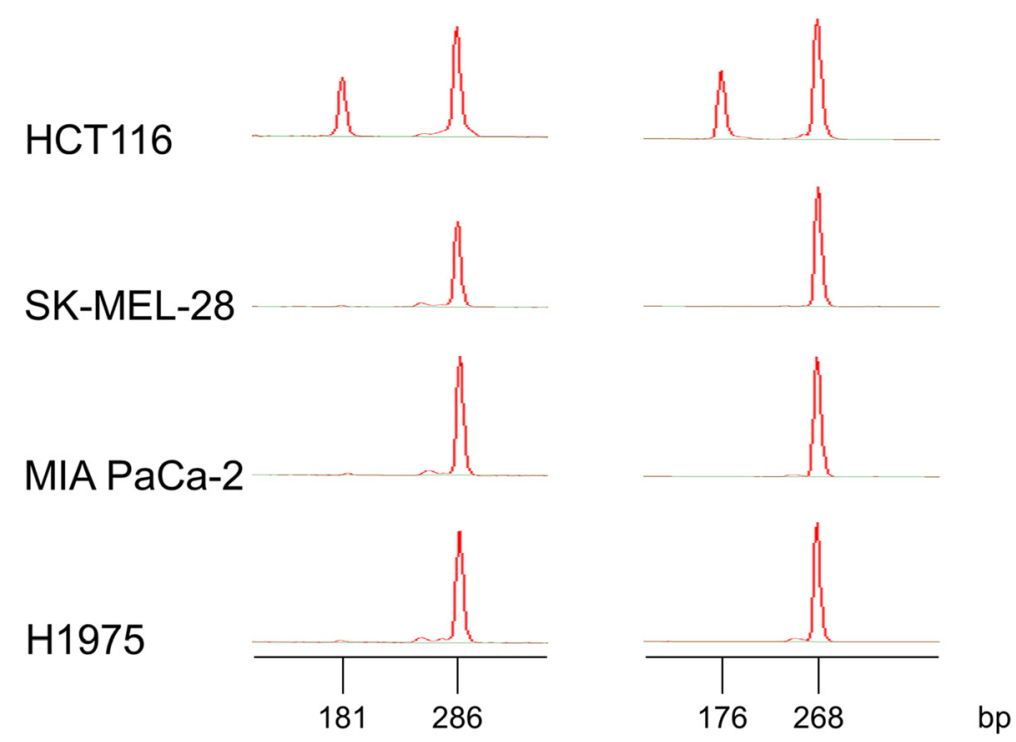

Fig. 3 Multiplex ASPCR results. Novel variants found in the SMAD4 and RET genes were confirmed by ASPCR and capillary electrophoresis using Lab-on-a-Chip technology performed on the 4 cell lines used in this study. For the SMAD4 gene, the 286 bp peak corresponds to a conserved region encompassing the C>T variant at the 48,586,344 position in the hg19 reference genome and the 181 bp peak corresponds to the variantspecific amplicon. For the RET gene, the 268 bp peak corresponds to a conserved region encompassing the A> G variant at the 43,615,612 position in the hg19 reference genome, and the $176 \mathrm{bp}$ peak corresponds to the variant-specific amplicon 
Table 4 Cutoff values for lon Torrent PGM sequencing and TVC parameters

\begin{tabular}{llllll}
\hline & Mean & S.D. & $\begin{array}{l}\text { Confidence } \\
\text { Level }\end{array}$ & $z$ & $\begin{array}{l}\text { Cutoff } \\
\text { (at z-score) }\end{array}$ \\
\hline Coverage & 1231 & 526 & $95 \%$ & 199 & 200 \\
$\begin{array}{l}\text { Number of } \\
\geq \text { Q20 bases }\end{array}$ & $2.5 \mathrm{E}+07$ & $2.4 \mathrm{E}+06$ & $95 \%$ & $2.0 \mathrm{E}+07$ & $2.0 \mathrm{E}+07$ \\
$\begin{array}{l}\text { Quality } \\
\text { (log } 10\end{array}$ & 3.65 & 0.45 & $99 \%$ & 2.48 & $300^{\mathrm{a}}$ \\
$\begin{array}{l}\text { Strand Bias } \\
\text { Strand }\end{array}$ & 0.7 & 0.04 & $99 \%$ & 0.79 & 0.79 \\
\hline
\end{tabular}

S.D., standard deviation; $a$, anti-logarithm of the found $z$ value

[19] with those reported by others sequencing the same genomic regions (Life Technologies, Carlsbad, CA).

\section{Effect of formalin fixation and Laser Capture Microdissection (LCM)}

In order to assess the potential effects of formalin fixation on variant identification, we sequenced DNA isolated from fresh-frozen cell lines and from DNA isolated from FFPE cell pellets prepared from the same cell lines. We then compared the variants identified in the fresh-frozen cell lines and their FFPE counterparts. Excellent Pearson's correlations were observed for all the variant frequencies identified in each pair of samples (i.e. MIA-PaCa-2 $r=0.989$, HCT116 $r=0.986$, SK-MEL-28 $r=$ 0.995, H1975 $r=0.992 ; \mathrm{p}<0.001$ ).

In addition, we assessed the potential effects of Laser Capture Microdissection (LCM) on variant detection by sequencing DNA isolated from a whole tissue section from a NSCLC case, containing near $70 \%$ neoplastic cells, and from DNA isolated from tumor cells enriched by LCM from the same case. We then compared the variants and their frequencies identified in each sample type. An excellent Pearson's correlation $\left(r=0.909, p=7.3 \times 10^{-8}\right)$ was observed between the two sample types, while Pathogenic/Likely Pathogenic somatic variants, such as EGFR NM_005228.3: c.2307_2308insGCCAGCGTG (p.Val769_Asp770insAlaSerVal) and TP53 NM_000546.5: c.659A > G (p.Tyr220Cys) were over-represented (i.e. at higher allelic variant frequencies) in the LCM sample compared to the whole tissue sample, as expected.

\section{VariantCaller plugin parameters}

The seven barcoded FFPE cell line mix samples with known variant frequencies were used to establish cutoff values for critical run and TVC parameters to achieve enough stringency (fewer false positives), while maintaining high sensitivity (fewer false negatives) in the

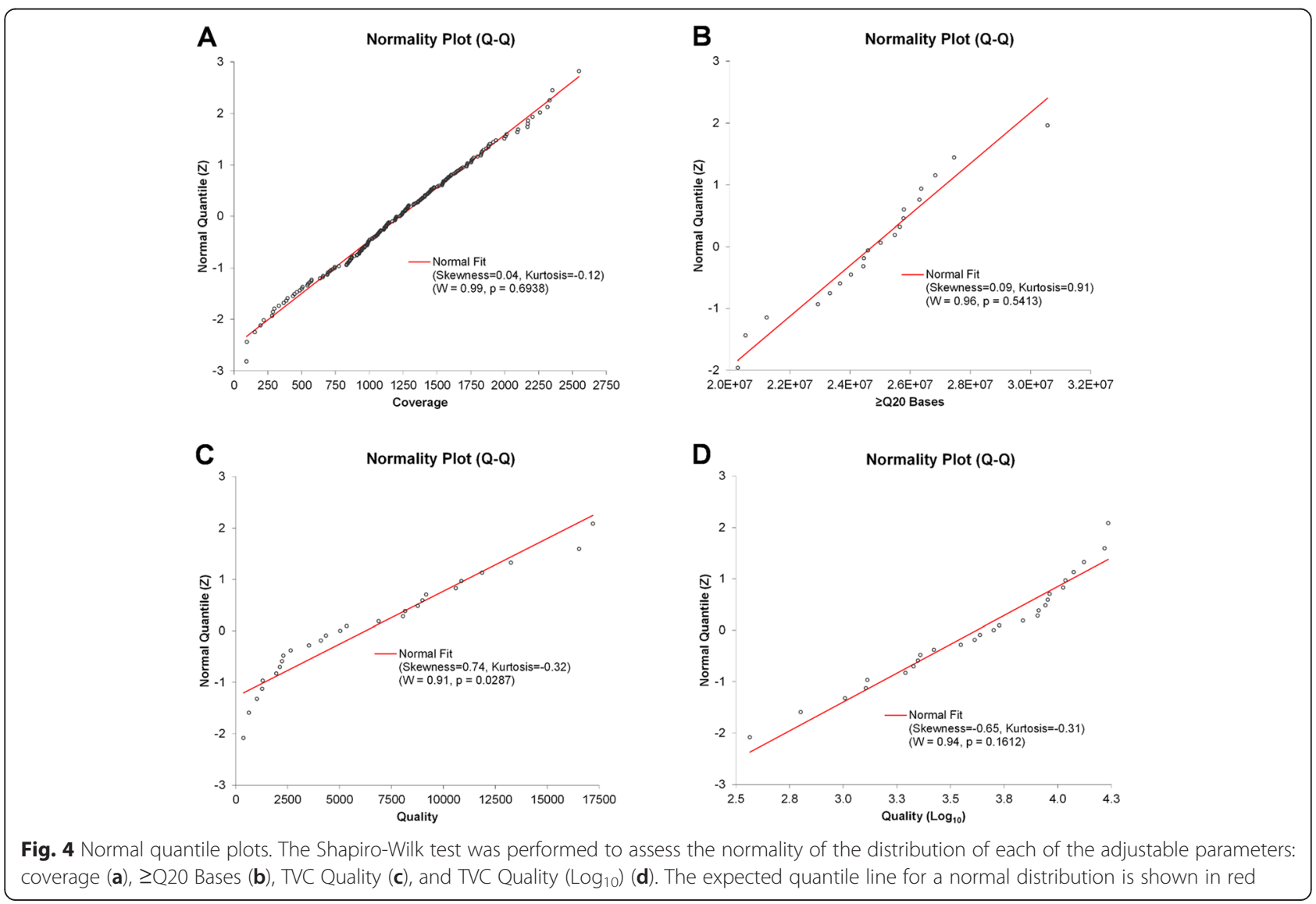


Table 5 Clinical specimen results for known KRAS, EGFR and BRAF mutations

\begin{tabular}{|c|c|c|}
\hline \multirow[b]{2}{*}{ Sample_ID } & \multicolumn{2}{|l|}{ KRAS or EGFR or BRAF Mutation Status } \\
\hline & Single-Gene Assay & CHP2 Assay \\
\hline DNA_01 & EGFR c.2369C > T (p.Thr790Met) & EGFR c.2369C > T (p.Thr790Met) \\
\hline DNA_02 & EGFR c.2156G > C p.Gly719Ala & EGFR c.2156G > C p.Gly719Ala \\
\hline DNA_03 & Negative & Negative \\
\hline DNA_04 & Negative & Negative \\
\hline DNA_05 & EGFR Exon 20 INS & EGFR c.2307_2308ins9 (p.V769_D770insASV) \\
\hline DNA_06 & Negative & Negative \\
\hline DNA_07 & Negative & Negative \\
\hline DNA_08 & EGFR c.2369C > T (p.Thr790Met) & EGFR c.2369C > T (p.Thr790Met) \\
\hline DNA_09 & EGFR c.2369C > T (p.Thr790Met) & EGFR c.2369C > T (p.Thr790Met) \\
\hline DNA_10 & EGFR Exon 19 DEL & EGFR c.2236_2250del15 (p.E746_A750delELREA) \\
\hline DNA_11 & Negative & Negative \\
\hline DNA_12 & Negative & Negative \\
\hline DNA_13 & Negative & Negative \\
\hline DNA_14 & Negative & Negative \\
\hline DNA_15 & Negative & Negative \\
\hline DNA_16 & Negative & Negative \\
\hline DNA_17 & Negative & Negative \\
\hline DNA_18 & Negative & Negative \\
\hline DNA_19 & Negative & Negative \\
\hline DNA_20 & Negative & Negative \\
\hline DNA_21 & KRAS c.35G > T (p.Gly12Val) & KRAS c.35G > T (p.Gly12Val) \\
\hline DNA_22 & Negative & Negative \\
\hline DNA_23 & EGFR c.2582 T> A (p.Leu861Gln) & EGFR c.2582 T> A (p.Leu861Gln) \\
\hline DNA_24 & EGFR c.2582 T> A (p.Leu861Gln) & EGFR c.2582 T> A (p.Leu861Gln) \\
\hline DNA_25 & Negative & Negative \\
\hline DNA_26 & BRAF c.1799 T > A (p.Val600Glu) & BRAF c.1799 T > A (p.Val600Glu) \\
\hline DNA_27 & KRAS c.34G > A (p.Gly12Ser) & c.34G > A (p.Gly12Ser) \\
\hline DNA_28 & Negative & Negative \\
\hline DNA_29 & EGFR c.2155G > A (p.Gly719Ser) & EGFR c.2155G > A (p.Gly719Ser) \\
\hline DNA_30 & Negative & Negative \\
\hline DNA_31 & Negative & Negative \\
\hline DNA_32 & KRAS c.34G > T (p.Gly12Cys) & c.34G > T (p.Gly12Cys) \\
\hline DNA_33 & BRAF c.1798_1799delGTinsAA (p.Val600Lys) & BRAF c.1798_1799delGTinsAA (p.Val600Lys) \\
\hline DNA_34 & BRAF c.1798_1799delGTinsAA (p.Val600Lys) & BRAF c.1798_1799delGTinsAA (p.Val600Lys) \\
\hline DNA_35 & EGFR Exon 19 DEL & EGFR c.2235_2246del12 (p.Glu746_Glu749del) \\
\hline DNA_36 & Negative & Negative \\
\hline DNA_37 & EGFR c.2573 T> G (p.Leu858Arg) & EGFR c.2573 T> G (p.Leu858Arg) \\
\hline DNA_38 & EGFR c.2573 T> G (p.Leu858Arg) & EGFR c.2573 T> G (p.Leu858Arg) \\
\hline DNA_39 & KRAS c.34G > T (p.Gly12Cys) & c.34G > T (p.Gly12Cys) \\
\hline DNA_40 & Negative & Negative \\
\hline DNA_41 & KRAS c.38G > A (p.Gly13Asp) & c.38G > A (p.Gly13Asp) \\
\hline DNA_42 & KRAS c.38G > A (p.Gly13Asp) & c.38G > A (p.Gly13Asp) \\
\hline DNA_43 & EGFR c.2573 T> G (p.Leu858Arg) & Negative \\
\hline
\end{tabular}


Table 5 Clinical specimen results for known KRAS, EGFR and BRAF mutations (Continued)

\begin{tabular}{lll}
\hline DNA_44 & EGFR Exon 20 INS & c.2312_2314dupACC (p.Pro772delinsHisPro) \\
DNA_45 & Negative & Negative \\
DNA_46 & Negative & Negative \\
DNA_47 & KRAS c.35G $>$ T (p.Gly12Val) & $c .35 G>T$ (p.Gly12Val) \\
DNA_48 & Negative & Negative \\
DNA_49 & Negative & Negative \\
DNA_50 & BRAF c.1799 T > A (p.V600Glu) & c.1799 T > A (p.V600Glu) \\
DNA_51 & KRAS c.35G $>$ A (p.Gly12Asp) & $c .35 G>A(p . G l y 12 A s p)$ \\
DNA_52 & BRAF c.1799 T > A (p.Val600Glu) & BRAF c.1799 T > A (p.Val600Glu) \\
DNA_53 & KRAS c.35G $>$ T (p.Gly12Val) & KRAS c.35G $>$ T (p.Gly12Val) \\
DNA_54 & EGFR c.2573 T > G (p.Leu858Arg) & EGFR c.2573 T > G (p.Leu858Arg) \\
DNA_55 & BRAF c.1799 T > A (p.Val600Glu) & BRAF c.1799 T $>$ A (p.Val600Glu) \\
\hline
\end{tabular}

variant calling process. Critical parameters, including those chosen to customize the TVC plugin, with their $\mathrm{z}$ and cutoff values, are listed in Table 4. Graphical representations of the Shapiro-Wilk normality test for three of the critical parameters are shown in Fig. 4. Thus, based on the normal distribution of the critical parameters, the established cutoff values were used as custom TVC plugin parameters, which were recorded in a JSON text format. The TVC Quality parameter failed to show a normal distribution, but the $\log _{10}$-transformed Quality values did. Thus, a $\log _{10}$-transformed cutoff value was calculated, instead.

\section{Clinical specimens}

After processing the previously tested 55 clinical specimens, we compared the KRAS, BRAF and EGFR variants obtained by NGS with our previous single gene assay results (Table 5). One clinical sample showed a L858R mutation in the EGFR gene using the single gene assay, which has a LoD of $1 \%$ of mutant allelic frequency, in the context of normal DNA, but that variant was undetectable in the CHP2 assay. Upon visualizing the BAM file with the IGV tool, we found that the variant was present in $<4 \%$ of the reads (Fig. 5), therefore below the LoD of the NGS-based assay. Thus, we found that the CHP2 assay performs with $96.7 \%$ sensitivity and $100.0 \%$ specificity for these three genes, when compared to single gene assays, which have a LoD of $1 \%$ for $B R A F$ and $E G F R$, and $5 \%$ for $K R A S$.

\section{Common variants and artifacts}

From the variants found in the 55 archived clinical samples, the four cell lines and the reference DNA sample NA12878, we observed a number of recurrent variants that seem to be detected in the majority of the samples. A list of these common variants is shown in Table 6. Some of the variants correspond to sequencing artifacts, such as homopolymers [13]. Other variants seem to systematically occur at the end of an amplicon, and others seem to correspond to SNPs with a high global minor allele frequency (MAF) (e.g., rs1050171 [A/G], MAF A: 0.4183).

\section{Performance of the Quality Control (QC) Material}

We have developed and implemented a high quality and cost-effective control material for routine utilization in the CHP2 assay on FFPE samples. This QC material consists of a FFPE mixture of cell lines derived from pancreatic (MIA-PaCa-2), colon (HCT116), melanoma (SK-MEL28) and lung (H1975) cancer. This cell line mixture was created to assess 8 somatic variants, including $7 \mathrm{SNVs}$ and 1 small DEL located in five different genes (BRAF, EGFR, KRAS, PIK3CA, and CTNNB1) at different allelic frequencies, and was subjected to formalin fixation and paraffin embedding to mimic routine FFPE clinical specimens. The performance characteristics of the QC material were established over 10 consecutive runs. Average reads on target for the QC material was $95.13 \%$ $\pm 2.33 \%$ and average uniformity on target areas was $98.26 \% \pm 0.68 \%$. During the initial 10 consecutive runs, all expected somatic variants in the QC material were consistently called at variant frequencies ranging from $9.1 \%(\mathrm{CV}=11.1 \%)$ to $37.9 \%(\mathrm{CV}=2.8 \%)$ (Table 7). Subsequently, for every batch/run, DNA isolated from a single $10-\mu \mathrm{m}$ section of this cell mixture block was barcoded along with other six samples, and the allele frequencies for variants called on the five genes were recorded and plotted in Levey-Jennings charts for every clinical run (Fig. 6).

\section{Discussion}

In the recent years, NGS has been mainly used in genomicbased research projects. The advent of cost-effective desktop instruments, such as the Illumina MiSeq and the Ion Torrent PGM, enabled the transition of NGS from genomic research into the clinical arena. In order 


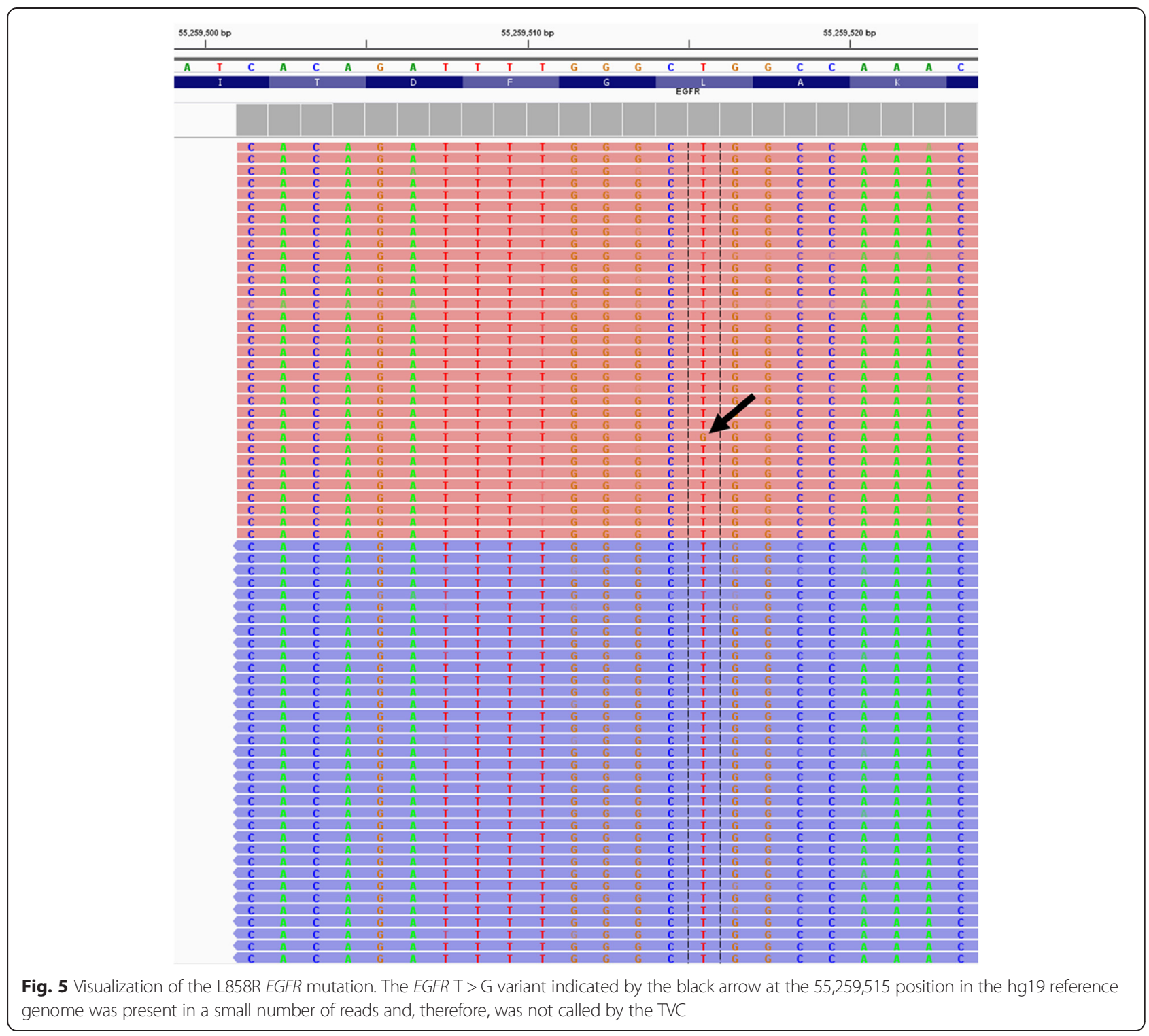

Table 6 List of common variants

\begin{tabular}{ll}
\hline Gene_Position_Variant & Class \\
\hline EGFR_55249063_G > A & High Allele Frequency SNP \\
FGFR3_1807894_G > A & High Allele Frequency SNP \\
FLT3_28610183_T > C & High Allele Frequency SNP \\
PDGFRA_55141055_A > G & High Allele Frequency SNP \\
CSF1R_149433596_A >C & End of Amplicon \\
CSF1R_149433597_C > T & End of Amplicon \\
STK11_1220321_T >C & Homopolymer \\
PTEN_89711834_INS > T & Homopolymer \\
RB1_48953805_DEL > A & Homopolymer \\
\hline
\end{tabular}

for NGS technology to translate into clinical testing, it must meet the rigorous quality assurance and quality control protocols used in CLIA-certified laboratories and be used on a routine basis, replacing single-gene assays. This transition has already started, primarily for rare inherited disorders, including prenatal testing, and cancer theragnosis.

In this study, we assessed the performance characteristics of the Ion AmpliSeq ${ }^{\text {ma }}$ Cancer Hotspot Panel v2 (CHP2) assay by sequencing well-characterized cell lines derived from pancreatic, colorectal, lung cancer, and melanoma, as well as different mixtures of fresh-frozen and FFPE DNA isolated from these cell lines. Thus, we assessed the sensitivity of the CHP2 assay in detecting low frequency somatic variants, or the assay's limit of detection (LoD), as well as the assay's precision and 
Table 7 Performance characteristics of the QC material

\begin{tabular}{lllllll}
\hline $\begin{array}{l}\text { Gene } \\
\text { Symbol }\end{array}$ & $\begin{array}{l}\text { hg19 } \\
\text { Coordinates }\end{array}$ & $\begin{array}{l}\text { Variant } \\
\text { Type }\end{array}$ & $\begin{array}{l}\text { Variant } \\
\text { Mean } \\
\text { Frequency } \\
(\%)\end{array}$ & $\begin{array}{l}\text { Standard } \\
\text { Deviation }\end{array}$ & \%CV \\
\hline BRAF & 140453136 & SNV & A & 18.5 & 1.5 & $7.9 \%$ \\
EGFR & 55242487 & SNV & T & 17.1 & 1.4 & $7.9 \%$ \\
EGFR & 55249071 & SNV & T & 28.6 & 1.7 & $6.1 \%$ \\
EGFR & 55259515 & SNV & G & 23.4 & 1.5 & $6.5 \%$ \\
KRAS & 25398281 & SNV & A & 9.6 & 0.7 & $7.0 \%$ \\
KRAS & 25398285 & SNV & T & 37.9 & 1.1 & $2.8 \%$ \\
PIK3CA & 178952085 & SNV & G & 9.1 & 1.0 & $11.1 \%$ \\
CTNNB1 & 41266134 & DEL & CTT & 11.5 & 2.0 & $17.8 \%$ \\
\hline
\end{tabular}

accuracy. In addition we evaluated the effects of sample barcoding, formalin fixation and paraffin embedding, as well as the impact of performing laser capture microdissection, on variant calling for these samples.

By establishing sequencing run quality control and variantCaller (TVC) cutoff parameters, we were able to customize the analysis pipeline for the CHP2 assay. Thus, we assessed the accuracy of the assay by sequencing 55 archival DNA samples, previously tested on single-gene mutational analysis assays, as well as one DNA sample from the HapMap project [19].

Overall, our results show that the $\mathrm{CHP} 2$ assay has a LoD of $4 \%$ of allelic frequency when barcoding up to 7 fresh-frozen and FFPE-derived DNA samples in a single Ion $316^{\mathrm{TM}}$ chip, with good precision as shown by excellent repeatability (intra-run) and reproducibility (interrun) metrics. Likewise, the CHP2 assay showed high accuracy when correlating the variants found on DNA isolated from the HCT116 and SK-MEL-28 cell lines, which have been previously analyzed by WES by the Genomics and Bioinformatics Group (GBG) from NCI [18]. Thus, we found that 19 out of the 21 variants had previously been identified by the NCI's GBG. The two unconfirmed variants seen in our laboratory were further identified by ASPCR assays, confirming that these two variants might be specific to the cell lines grown in our laboratory, and not a sequencing artifact. Moreover, we found an excellent correlation with previously reported variants and their frequencies for the well-characterized reference DNA sample NA12878 from the HapMap project [19]. The fact that all-21 variants found in the SK-MEL-28 and HCT116 DNA samples by the CHP2 assay were confirmed by WES by the GBG from NCI, or by ASPCR as presented here, allows us to confidently report somatic variants detected in clinical specimens, when all the QC criteria presented in this study are met in the clinical run. This is in line with a recently published study that concludes that confirmatory analysis by Sanger sequencing of variants detected by NGS testing that meets appropriate quality thresholds is "unnecessarily redundant" [23].

Furthermore, when sequencing previously tested 55 clinical specimens, we found that the $\mathrm{CHP} 2$ assay performs with $96.7 \%$ sensitivity and $100.0 \%$ specificity for the KRAS, BRAF and EGFR genes, when compared to single gene assays results, using as little as 1-10 ng of FFPE DNA as template. In addition, we have identified common variants that were called in the majority of the samples, and we were able to ascertain that they correspond to either sequencing artifacts or to SNPs with a high global MAF. Thus, we were able to flag these common variant in our analysis pipeline, to not include them in the final report.

It has been recommended that, in order to assure the quality of this, or any NGS-based assay in routine clinical laboratory practice, efforts should be made to establish a suitable and robust reference or control material, and the sequence of such control material could be used to monitor quality as the technology and/or the analysis
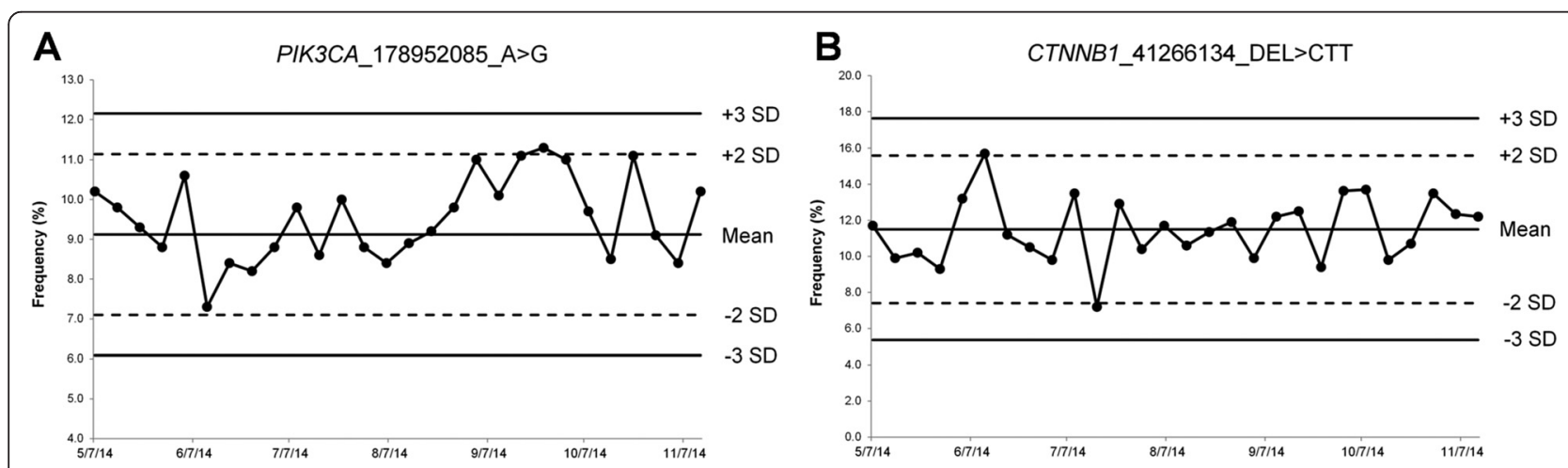

Fig. 6 Continuous monitoring of the QC material using Levey-Jennings plots. The lowest frequency of a SNV (a) and of a small DEL (b) from the 8 variants detected in the QC material listed in Table 7 were monitored on each run over a period of 6 months using Levey-Jennings plots. The plots show the expected mean value, previously assessed by 10 independent runs, as well as expected limits: two standard deviations (SD) (hatched lines), and three SD (solid lines). All variants frequencies are within three standard deviations of the mean expected value 
pipeline evolve. Such a control material should be well characterized and have similar variants as those targeted by the assay, and should include SNVs and Indels. These variants may be pathogenic or not, and should be located in genomic regions targeted by the assay [24].

Therefore, we developed and tested a quality control (QC) material by mixing, fixing and embedding the four cell lines used in the assay validation process. The performance characteristics of this control were assessed during 10 independent consecutive runs and mean and ranges were established to monitor each clinical run thereafter. The fact that the QC material was created on a patient-like matrix (i.e., FFPE cell block) makes it an excellent quality control material to monitor every step of the assay, from DNA extraction to data analysis pipeline and variant calling. Also, since a single $10-\mu \mathrm{m}$ section is used in each batch of samples for a run, the costs of running this QC material are dramatically lower than those of running some commercially available materials. Moreover, the robust performance characteristics of such QC material ensures the generation of high quality sequence data from NGS testing of FFPE specimens, even close to the limit of detection of the assay. It is worth noting that, even though we have shown that we are able to consistently call variants at low frequencies, near $9 \%$, in the QC material presented here, this alone does not ensure that variants at lower frequencies (i.e. $<9 \%$ ) will be confidently called by the assay in every run. A thorough analytical validation, specifically well-designed experiments to assess the LoD of the assay, is required to ensure that low frequency variants are reliably called by targeted NGS assays for somatic testing of FFPE specimens.

\section{Conclusions}

In summary, during the validation process of the CHP2 assay, we have been able to customize the analysis pipeline, including the variant calling process, resulting in a highly sensitive, precise and accurate clinical assay. Moreover, we successfully developed a robust QC material that ensures consistent patient results in every clinical run. Even more importantly, this QC material, with a relative low manufacturing cost, has been instrumental to assess the performance of the CHP2 assay after each instrument preventive maintenance service, as well as minor software upgrades, which are prone to occur frequently in this rapidly evolving field.

\section{Competing interests}

The authors declare that they have no competing interests.

\section{Authors' contributions}

CID, CNP and AFG conceived the study. CID and JAA designed the quality control material; JAA prepared the quality control material; CID analyzed the data and drafted the manuscript. All authors read and approved the final manuscript.

\section{Acknowledgements}

We would like to thank Mark Voelkner, Paula Anderson, Guoyan Gao and Pamela Morris for technical assistance in the cell line culture and processing, and in running the CHP2 assay for this study.

Received: 20 July 2015 Accepted: 28 August 2015

Published online: 17 September 2015

\section{References}

1. Bass AJ, Thorsson V, Shmulevich I, Reynolds SM. Comprehensive molecular characterization of gastric adenocarcinoma. Nature. 2014;513:202-9.

2. Celiku O, Johnson S, Zhao S, Camphausen K, Shankavaram U. Visualizing molecular profiles of glioblastoma with GBM-BioDP. PLoS One. 2014;9:e101239.

3. Chen Y, McGee J, Chen X, Doman TN, Gong X, Zhang Y, et al. Identification of druggable cancer driver genes amplified across TCGA datasets. PLoS One. 2014;9:e98293.

4. Collins I, Workman P. New approaches to molecular cancer therapeutics. Nat Chem Biol. 2006;2:689-700.

5. Ciombor KK, Wu C, Goldberg RM. Recent therapeutic advances in the treatment of colorectal cancer. Annu Rev Med. 2015;66:83-95.

6. Dumur $\mathrm{Cl}$, Idowu $\mathrm{MO}$, Powers $\mathrm{CN}$. Targeting tyrosine kinases in cancer: the converging roles of cytopathology and molecular pathology in the era of genomic medicine. Cancer Cytopathol. 2013;121:61-71.

7. Paez JG, Janne PA, Lee JC, Tracy S, Greulich H, Gabriel S, et al. EGFR mutations in lung cancer: correlation with clinical response to gefitinib therapy. Science. 2004;304:1497-500.

8. Flaherty KT, Puzanov I, Kim KB, Ribas A, McArthur GA, Sosman JA, et al. Inhibition of mutated, activated BRAF in metastatic melanoma. N Engl J Med. 2010;363:809-19.

9. De Roock W, Jonker DJ, Di Nicolantonio F, Sartore-Bianchi A, Tu D, Siena S, et al. Association of KRAS p.G13D mutation with outcome in patients with chemotherapy-refractory metastatic colorectal cancer treated with cetuximab. JAMA. 2010;304:1812-20.

10. Dumur $\mathrm{Cl}$. Available resources and challenges for the clinical annotation of somatic variations. Cancer Cytopathol. 2014;122:730-6.

11. Kanagal-Shamanna R, Portier BP, Singh RR, Routbort MJ, Aldape KD, Handal $B A$, et al. Next-generation sequencing-based multi-gene mutation profiling of solid tumors using fine needle aspiration samples: promises and challenges for routine clinical diagnostics. Mod Pathol. 2014;27:314-27.

12. Luthra R, Patel KP, Reddy NG, Haghshenas V, Routbort MJ, Harmon MA, et al. Next-generation sequencing-based multigene mutational screening for acute myeloid leukemia using MiSeq: applicability for diagnostics and disease monitoring. Haematologica. 2014;99:465-73.

13. Singh RR, Patel KP, Routbort MJ, Reddy NG, Barkoh BA, Handal B, et al. Clinical validation of a next-generation sequencing screen for mutational hotspots in 46 cancer-related genes. J Mol Diagn. 2013;15:607-22.

14. Tsongalis GJ, Peterson JD, de Abreu FB, Tunkey CD, Gallagher TL, Strausbaugh LD, et al. Routine use of the Ion Torrent AmpliSeq Cancer Hotspot Panel for identification of clinically actionable somatic mutations. Clin Chem Lab Med. 2014;52:707-14.

15. Clinical and Laboratory Standards Institute. Molecular Methods for Clinical Genetics and Oncology Testing; Approved Guideline; Third Edition. CLSI document MM01-A3. Wayne, PA:CLSI. 2012.

16. Li J, Wang L, Mamon H, Kulke MH, Berbeco R, Makrigiorgos GM. Replacing PCR with COLD-PCR enriches variant DNA sequences and redefines the sensitivity of genetic testing. Nat Med. 2008;14:579-84.

17. Newton CR, Graham A, Heptinstall LE, Powell SJ, Summers C, Kalsheker N, et al. Analysis of any point mutation in DNA. The amplification refractory mutation system (ARMS). Nucleic Acids Res. 1989;17:2503-16.

18. Reinhold WC, Varma S, Sousa F, Sunshine M, Abaan OD, Davis SR, et al. $\mathrm{NCl}-60$ whole exome sequencing and pharmacological Cell Miner analyses. PLoS One. 2014;9:e101670.

19. Duitama J, McEwen GK, Huebsch T, Palczewski S, Schulz S, Verstrepen K et al. Fosmid-based whole genome haplotyping of a HapMap trio child: evaluation of Single Individual Haplotyping techniques. Nucleic Acids Res. 2012:40:2041-53.

20. Robinson JT, Thorvaldsdottir H, Winckler W, Guttman M, Lander ES, Getz G, et al. Integrative genomics viewer. Nat Biotechnol. 2011;29:24-6.

21. Garrison E, Marth G. Haplotype-based variant detection from short-read sequencing. arXiv preprint arXiv. 2012;1207:3907. 
22. Shapiro SS, Wilk MB. An analysis of variance test for normality (complete samples). Biometrika. 1965;52:591-611.

23. Baudhuin LM, Lagerstedt SA, Klee EW, Fadra N, Oglesbee D, Ferber MJ. Confirming variants in next-generation sequencing panel testing by Sanger sequencing. J Mol Diagn. 2015;17:456-61.

24. Gargis AS, Kalman L, Berry MW, Bick DP, Dimmock DP, Hambuch T, et al. Assuring the quality of next-generation sequencing in clinical laboratory practice. Nat Biotechnol. 2012;30:1033-6.

Submit your next manuscript to BioMed Central and take full advantage of:

- Convenient online submission

- Thorough peer review

- No space constraints or color figure charges

- Immediate publication on acceptance

- Inclusion in PubMed, CAS, Scopus and Google Scholar

- Research which is freely available for redistribution 